Article

\title{
The E3 Ubiquitin Ligase Gene Sl1 Is Critical for Cadmium Tolerance in Solanum lycopersicum L.
}

\author{
Chen-Xu Liu ${ }^{1}$, Ting Yang ${ }^{1}{ }^{\mathbb{D}}$, Hui Zhou ${ }^{1}$, Golam Jalal Ahammed ${ }^{2, *} \mathbb{C}$, Zhen-Yu Qi ${ }^{3}$ and Jie Zhou ${ }^{1,4,5, * \mathbb{C}}$ \\ 1 Zhejiang Provincial Key Laboratory of Horticultural Plant Integrative Biology, Department of Horticulture, \\ Zhejiang University, Yuhangtang Road 866, Hangzhou 310058, China; chenxuliu@zju.edu.cn (C.-X.L.); \\ 22116163@zju.edu.cn (T.Y.); 3180100610@zju.edu.cn (H.Z.) \\ 2 College of Horticulture and Plant Protection, Henan University of Science and Technology, \\ Luoyang 471023, China \\ 3 Agricultural Experiment Station, Zhejiang University, Hangzhou 310058, China; qizhenyu@zju.edu.cn \\ 4 Key Laboratory of Horticultural Plants Growth, Development and Quality Improvement, \\ Agricultural Ministry of China, Yuhangtang Road 866, Hangzhou 310058, China \\ 5 Shandong (Linyi) Institute of Modern Agriculture, Zhejiang University, Linyi 276000, China \\ * Correspondence: ahammed@haust.edu.cn (G.J.A.); jie@zju.edu.cn (J.Z.)
}

check for updates

Citation: Liu, C.-X.; Yang, T.; Zhou, H.; Ahammed, G.J.; Qi, Z.-Y.; Zhou, J. The E3 Ubiquitin Ligase Gene Sl1 Is Critical for Cadmium Tolerance in Solanum lycopersicum L. Antioxidants 2022, 11, 456. https:// doi.org/10.3390/antiox11030456

Academic Editor: Nafees A. Khan

Received: 22 January 2022

Accepted: 23 February 2022

Published: 25 February 2022

Publisher's Note: MDPI stays neutral with regard to jurisdictional claims in published maps and institutional affiliations.

Copyright: (C) 2022 by the authors. Licensee MDPI, Basel, Switzerland. This article is an open access article distributed under the terms and conditions of the Creative Commons Attribution (CC BY) license (https:// creativecommons.org/licenses/by/ $4.0 /)$.

\begin{abstract}
Heavy metal cadmium (Cd) at high concentrations severely disturbs plant growth and development. The E3 ubiquitin ligase involved in protein degradation is critical for plant tolerance to abiotic stress, but the role of E3 ubiquitin ligases in Cd tolerance is largely unknown in tomato. Here, we characterized an E3 ubiquitin ligase gene Sl1, which was highly expressed in roots under $\mathrm{Cd}$ stress in our previous study. The subcellular localization of S11 revealed that it was located in plasma membranes. In vitro ubiquitination assays confirmed that S11 had E3 ubiquitin ligase activity. Knockout of the Sl1 gene by CRISPR/Cas9 genome editing technology reduced while its overexpression increased $\mathrm{Cd}$ tolerance as reflected by the changes in the actual quantum efficiency of PSII photochemistry $\left(\Phi_{\text {PSII }}\right)$ and hydrogen peroxide $\left(\mathrm{H}_{2} \mathrm{O}_{2}\right)$ accumulation. Cd-induced increased activities of antioxidant enzymes including superoxide dismutase (SOD), catalase (CAT), ascorbate peroxidase (APX), and glutathione reductase (GR) were compromised in sl1 mutants but were enhanced in Sl1 overexpressing lines. Furthermore, the content of $\mathrm{Cd}$ in both shoots and roots increased in sl1 mutants while reduced in Sl1 overexpressing plants. Gene expression assays revealed that S11 regulated the transcript levels of heavy metal transport-related genes to inhibit $\mathrm{Cd}$ accumulation. These findings demonstrate that S11 plays a critical role in regulating $\mathrm{Cd}$ tolerance by relieving oxidative stress and resisting heavy metal transportation in tomato. The study provides a new understanding of the mechanism of plant tolerance to heavy metal stress.
\end{abstract}

Keywords: antioxidant enzymes; heavy metal stress; ubiquitination; protein degradation; tomato

\section{Introduction}

The rapid development of industrialization and urbanization has resulted in severe environmental pollution [1]. Sewage or waste produced by industries and garbage generated by anthropogenic activities lead to the release of heavy metals into the environment, causing contamination of agricultural soil and water [2,3]. Thus, heavy metal pollution affects both human health as well as plant health, particularly plant growth and development [4].

Cadmium (Cd), a toxic heavy metal, severely inhibits plant growth and crop production when it occurs in high concentrations in soils or growth media [5]. The absorption and translocation of $\mathrm{Cd}$ in plants include distinct phases, such as the absorption of $\mathrm{Cd}$ in roots, the transportation of $\mathrm{Cd}$ into xylem and phloem, and the transportation of $\mathrm{Cd}$ into aboveground tissues [6]. The absorption and transportation of $\mathrm{Cd}$ in plants mainly depend on transport proteins such as heavy-metal-associated P-type ATPase family protein (HMA), 
ATP-binding cassette transporters $(\mathrm{ABC})$, natural resistance-associated macrophage protein (NRAMP), metal-tolerance protein (MTP), calcium exchanger protein (CAX), and zinc/iron-regulated transporter-like protein (ZRT/IRT) [6-12].

Owing to the interaction with the sulfhydryl group of proteins, $\mathrm{Cd}$ can affect the activity of multiple enzymes and the functions of proteins [13]. Hence, the accumulation of $\mathrm{Cd}$ in plant tissues disorders various growth, biochemical, and physiological processes, such as photosynthesis, antioxidant enzyme activity, cell structure, and plant morphology [13,14]. Specifically, Cd stress causes damage to chloroplast ultrastructure, inhibits pigment synthesis, and affects several photosynthesis-related protein complexes [15]. Cd stress also impairs the balance between reactive oxygen species (ROS) production and ROS scavenging [16]. In particular, $\mathrm{Cd}$ stress disturbs the electron transfer chain in mitochondria and chloroplasts and activates NADPH oxidases, which cause excessive ROS accumulation and associated oxidative stress in plants $[17,18]$. Moreover, Cd stress induces protein denaturation, which disturbs the balance of protein quality in plant cells [19].

Plants have also evolved very diverse and complex defensive mechanisms for resisting heavy metal stress [20]. The ascorbate-glutathione (AsA-GSH) cycle is an indispensable pathway for eliminating oxidative stress [21]. Moreover, antioxidant enzymes including superoxide dismutase (SOD), catalase (CAT), ascorbate peroxidase (APX), peroxidase (POD), and glutathione reductase (GR) are vital for scavenging ROS [22]. Antioxidant GSH not only functions on relieving oxidative stress, but also participates in the synthesis of phytochelatins (PCs) in plants, which can bind with heavy metal ions [20,23,24]. Moreover, the protein quality control system needs chaperone proteins to refold the denatured proteins or operates a protein degradation system to clear misfolded proteins under Cd stress [24,25].

Ubiquitin proteasome system (UPS) has been recognized as a critical process to control the abundance, quality, and function of protein in cells [26,27]. Ubiquitin is an indispensable component of UPS, which acts as identifying target protein for degradation [28]. Ubiquitindependent protein degradation requires reactions of multiple ubiquitin-related enzymes, including ubiquitin activating enzyme (E1), ubiquitin conjugating enzyme (E2), and ubiquitin ligase (E3) $[29,30]$. The ubiquitin molecule is activated by E1 and then transferred to E2. The E3 interacts with E2-ubiquitin and targets proteins for labeling substrate protein with ubiquitin. Finally, the $26 \mathrm{~S}$ proteasome degrades the target proteins [31-33]. E3 ubiquitin ligases play critical roles in recognizing substrate proteins [29]. Among the ubiquitinrelated enzymes, E3 ubiquitin ligases have the largest family in plants [19]. The E3 ligase has been divided into three types, as follows: really interesting new gene (RING)-type, homology to E6-associated carboxyl-terminus (HECT)-type, and U-box-type [31].

RING-type E3 ubiquitin ligases have a cysteine-rich domain that can bind with $\mathrm{Zn}$ ions [31]. Previous studies have revealed that RING-type E3 ubiquitin ligases are involved in mediating plant tolerance of heavy metal stress [19,25,34]. A RING-type E3 ubiquitin ligase HIR1 confers tolerance of arsenic (As) and Cd stress in rice [34]. Overexpression of HIR1 increases root length in rice under As and Cd treatment. The E3 ubiquitin ligase protein HIR1 also interacts with tonoplast intrinsic protein TIP4; 1 and regulates its abundance in rice, thereby alleviating heavy metal stress [34]. Tomato E3 ubiquitin ligase RING1 increases Cd tolerance by minimizing ROS levels due to enhanced antioxidant enzyme activities $[19,25]$. However, the roles of many tomato E3 ubiquitin ligases are largely unknown, particularly in Cd stress.

In a previous study, we found that the expression of the RING-type E3 ubiquitin ligase Sl1 significantly increased in tomato roots when challenged with aluminum (Al) or Cd stress [25]. However, the precise role of Sl1 remains elusive. We hypothesized that Sl1 might play a crucial role in Cd tolerance in tomato plants. Here, we characterized the function of Sl1 by generating sl1 mutants and $S l 1$ overexpressing lines in tomato. Our study unveils a novel role of $S l 1$ in plant tolerance to Cd stress. 


\section{Materials and Methods}

\subsection{Plant Materials and Treatments}

In this study, tomato (Solanum lycopersicum L., Tomato Genetics Resource Center, Davis, CA, USA, https: / / tgrc.ucdavis.edu (accessed on 4 March 2018)) cultivar "Ailsa Craig" was used to generate sl1 mutants and Sl1 overexpressing transgenic lines.

Tomato seedlings were raised in vermiculite and transferred to a hydroponic jar $(40 \mathrm{~cm} \times 25 \mathrm{~cm} \times 15 \mathrm{~cm})$ containing Hoagland nutrient solution, when two real leaves of seedlings unfolded. The growth conditions were temperature of $23 / 20{ }^{\circ} \mathrm{C}$ (day/night), $14 \mathrm{~h}$ photoperiod, 60\% humidity, and photosynthetic photo flux density (PPFD) of $600 \mu \mathrm{mol} \mathrm{m} \mathrm{m}^{-2} \mathrm{~s}^{-1}$. For Cd treatment, seedlings at the five-leaf stage were treated with $100 \mu \mathrm{M} \mathrm{CdCl}_{2}$ and the hydroponic nutrient solution was changed every 5 days (d).

\subsection{Generation of Transgenic Plants}

The sl1 mutant was generated by CRISPR/Cas9 technique. For CRISPR vector construction, the target sequence used as sgRNA on the only exon of Sl1 was searched by the CRISPR-P program (http:/ / cbi.hzau.edu.cn/cgi-bin/CRISPR (accessed on 10 May 2019)). For deletion of a large fragment, two targets were selected (sgRNA-Sl1-254: TCATTAAAGGGTCTTCAACA and sgRNA-S11-564: GTTGAACTTGGAGCAATGAT), primers were then generated by adding adapter sequence to two ends of target sequences (Figure S1A). The sense and antisense sgRNA primers were annealed and inserted into the BbsI site of the AtU6-sgRNA-AtUBQCas 9 vector, then positive clones were confirmed by sequencing. The two clones were named sgRNA-Sl1-254 and sgRNA-Sl1-564. The fragment was amplified using the clone of sgRNA-S11-564 as a template, the fragment was then inserted into the backbone vector with Cas9 and sgRNA-254. pCAMBIA1301 was used as a binary expression vector, and the sgRNA-254-sgRNA-564-Cas9 was inserted into the EcoRI and HindIII site of pCAMBIA1301. Positive clones were transformed into Agrobacterium tumefaciens strain GV3101 for transgenic plant generation.

For the construction of Sl1 overexpressing transgenic lines, the full-length coding sequences (CDS) of Sl1 were amplified with primers (Forward primer 5'-TTACAATTACCATGGGGCGCGCCATGGATCTTGTTAGACTAAAGTATTTTGAA-3' ${ }^{\prime}$, Reverse verse primer 5'-AACATCGTATGGGTAGGTACCTGACTCTAACTGAATAGGTAAAACTACATTTC-3's), then inserted the PCR products into the AscI and KpnI site of pFGC1008-HA vector. The positive vector was confirmed by sequencing and then transformed into A. tumefaciens strain GV3101.

The detailed method of generation of transgenic lines was described previously [35]. Two independent homozygous lines of the F2 generation of Sl1 overexpressing plants were used in further experiments. Two homozygous lines of sl1 mutants without CRISPR/Cas 9 DNA were selected for further research. The special primers for mutant detection were designed as follows: Forward primer 5'-GCAGAGAGACAACATTCACCA- 3', Reverse primer 5'-AAAGTTGTCGATCCGTCGCT-3'.

\subsection{E3 Ubiquitin Ligase Activity Assay}

The full length CDS of Sl1 were amplified with the primers (Forward primer 5'GAGGGAAGGATTTCAGAATTCATGGATCTTGTTAGACTAAAGTATTTTGAA-3', Reverse primers 5'-CAGGTCGACTCTAGAGGATCCTGACTCTAACTGAATAGGTAAAACTACATTTC-3'). The PCR products were digested with restriction endonuclease EcoRI and $\mathrm{BamHI}$ and were then inserted into the pMAL-2c vector (New England Biolabs, Ipswich, MA, USA). The maltose-binding protein-empty vector (MBP-EV) and MBP-fused S11 protein were expressed in Escherichia coli strain BL21 (DE3) and purified with instructions of the manufacturer (New England Biolabs, Ipswich, MA, USA). The in vitro ubiquitination assay of S11 was performed by instructions described previously [36]. The reaction system was prepared as described previously [19].

After the reaction, a Western blot was used to detect whether the S11 protein has E3 ubiquitin ligase activity. Anti-His (A5C12; HUABIO, Hangzhou, China) and anti-MBP 
(MBP61R; Thermo Fisher Scientific, Waltham, MA, USA) antibodies were used in Western blot assay.

\subsection{Vector Construction and Subcellular Localization of Sl1}

The full length CDS of Sl1 were amplified with primers (Forward primer 5'-CTCTCGAGCTTTCGCGAGCTCATGGATCTTGTTAGACTAAAGTATTTTGAA-3', Reverse primer 5' GCCCTTGCTCACCATGGATCCTGACTCTAACTGAATAGGTAAAACTACATTTC- $3^{\prime}$ ), and the PCR products were inserted into $\mathrm{SacI}$ and BamHI site of pCAMBIA2300 with a GFP tag at the $\mathrm{C}$ terminus. The primers were designed by homologous recombination methods as described previously. After confirming positive clones by sequencing, the vector (35S-Sl1-GFP) and empty vector were transformed into A. tumefaciens strain GV3101. Transgenic Nicotiana benthamiana that expressed with nucleus-located signaling (RFP-H2B) was used for transient expression. The transient expression method was described previously [37]. For the fluorescence image acquisition, a Nikon A1 confocal microscope (Nikon, Tokyo, Japan) was used at $48 \mathrm{~h}$ post infiltration in tobacco leaves, and the excitation/emission wavelengths of GFP were $488 \mathrm{~nm} / 480-520 \mathrm{~nm}$, and the excitation/emission wavelengths of RFP were $561 \mathrm{~nm} / 610-630 \mathrm{~nm}$.

\subsection{Measurement of Actual Quantum Efficiency of PSII Photochemistry}

After $15 \mathrm{~d}$ treatment of $\mathrm{Cd}$, plants were dark-adapted for $30 \mathrm{~min}$ before measurement. The actual quantum efficiency of PSII photochemistry ( $\left.\Phi_{\text {PSII }}\right)$ was determined by the Imaging PAM (IMAG-MAXI, Heinz Walz, Germany) in the fifth fully expanded leaves as described previously [38].

\subsection{Measurements of Hydrogen Peroxide and Antioxidants Enzyme Activity}

Three-tenths gram of tomato root samples were collected and ground in liquid nitrogen. The samples were combined with $3 \mathrm{~mL}$ precooled $1 \mathrm{M} \mathrm{HClO}_{4}$ in a $10 \mathrm{~mL}$ centrifuge tube and mixed thoroughly. The $\mathrm{pH}$ of the sample was adjusted to 6-7 using $4 \mathrm{M} \mathrm{KOH}, 0.05 \mathrm{~g}$ activated carbon was then added to absorb pigments. The samples were centrifuged at $12,000 \times \mathrm{rpm}$ for $10 \mathrm{~min}$ at $4{ }^{\circ} \mathrm{C}$ and supernatants were collected in $5 \mathrm{~mL}$ tubes for reaction. The reaction buffer was as follows: $1 \mathrm{~mL}$ supernatant or $\mathrm{H}_{2} \mathrm{O}_{2}$, $996 \mu \mathrm{L} 1 \mathrm{mM}$ ABTS (dissolved in $100 \mathrm{mM}$ potassium acetate, $\mathrm{pH}$ 4.4), and $4 \mu \mathrm{L}$ POD (P8375, Merck KGaA, Darmstadt, Germany). The absorbance of reaction buffer was detected at a wavelength of $412 \mathrm{~nm}$ by a SHIMADZU UV-2410PC spectrophotometer (Shimadzu Company, Kyoto, Japan) and the content of $\mathrm{H}_{2} \mathrm{O}_{2}$ was calculated by a standard curve [39].

Three-tenths gram fresh tomato roots were ground in liquid nitrogen and dissolved in a precooled buffer that included $50 \mathrm{mM}$ phosphate buffered saline ( $\mathrm{pH}$ 7.8), $0.2 \mathrm{mM}$ EDTA, $2 \mathrm{mM}$ ascorbic acid, and $2 \%(w / v)$ poly-vinylpolypyrrolidone. The samples were mixed thoroughly using vortex and then centrifuged at $12,000 \times \mathrm{g}$ for $20 \mathrm{~min}$ at $4{ }^{\circ} \mathrm{C}$. The supernatant was collected in new centrifuge tubes for detecting enzyme activity. The method of measuring enzyme activities of SOD, CAT, APX, and GR was described previously [40].

\subsection{Measurement of $\mathrm{Cd}$ Content and $\mathrm{Cd}$ Localization}

Tomato leaves and roots were washed and collected in liquid nitrogen after $10 \mathrm{~d} \mathrm{Cd}$ treatment. Samples were put in the oven for $30 \mathrm{~min}$ at $115^{\circ} \mathrm{C}$ then transferred to $60{ }^{\circ} \mathrm{C}$ for total dryness. The dried sample was ground and mixed with an acid solution that contained $\mathrm{HClO}_{4}$ and $\mathrm{HNO}_{3}(1: 3, v: v)$. The samples were digested at $180{ }^{\circ} \mathrm{C}$ and the solution was then evaporated to $1-2 \mathrm{~mL}$ for dilution. The remained solution was diluted with deionized water to a final volume of $50 \mathrm{~mL}$ and inductively coupled plasma mass spectrometry (ICPMS-2030, Shimadzu Company, Kyoto, Japan) was used for determining Cd content [25].

For Cd localization, the Leadmium ${ }^{\mathrm{TM}}$ Green AM probe (Invitrogen, Carlsbad, CA, USA) was used for Cd staining according to the manufacturer's instructions. The root tips were stained by immersing in dye solution for $3 \mathrm{~h}$ in dark at room temperature; the sample 
was then washed three times with buffer $(0.85 \% \mathrm{NaCl})$. A Nikon A1 confocal microscope (Nikon, Tokyo, Japan) was used to detect the Cd localization, and the excitation/emission wavelengths of GFP were $488 \mathrm{~nm} / 510-530 \mathrm{~nm}$ [41]. The mean fluorescence intensity values of $\mathrm{Cd}$ stained root tips were detected by ImageJ 1.53 analysis software (National Institute of Health, Bellevue, WA, USA) and relative fluorescence intensity normalized to the intensity of the wild-type group under Cd stress.

\subsection{Total RNA Isolation and $q R T-P C R$ Analysis}

One-tenth gram tomato samples were collected in a $2 \mathrm{~mL}$ centrifuge tube and frozen in liquid nitrogen. An RNAprep pure plant kit (Tiangen Biotech, Beijing, China) was used for total RNA extraction according to the manufacturer's instructions. Five-tenths milligram total RNA was used to reverse transcribe to cDNA template by HiScript II Q RT SuperMix for qPCR Kit (Vazyme, Nanjing, China). qRT-PCR was conducted with ChamQ Universal SYBR qPCR Master Mix (Vazyme, Nanjing, China) on a Light Cycle 480 II Real-Time PCR detection system (Roche, Basel, Switzerland). The total $20 \mu \mathrm{L}$ reaction system was as follows: $10 \mu \mathrm{L}$ SYBR qPCR Master Mix, $1 \mu \mathrm{L}$ cDNA template, $10 \mu \mathrm{M}$ forward and reverse primer, and deionized water. The PCR program was performed with $30 \mathrm{~s}$ at $95^{\circ} \mathrm{C}$, followed with $35-40$ cycles of $10 \mathrm{~s}$ at $95{ }^{\circ} \mathrm{C}, 30 \mathrm{~s}$ at $58{ }^{\circ} \mathrm{C}$, and $1 \mathrm{~min}$ at $72{ }^{\circ} \mathrm{C}$. ACTIN was used for calculating the relative expression level of the target gene. The primers are listed in Table S1.

\subsection{Immunoblotting Assays}

The protein extraction and Western blot procedures were described previously [42,43]. The antibodies used in this assay included anti-HA (26183, Thermo Fisher Scientific, Waltham, MA, USA) and rabbit antimouse (ab6728, abcam, Cambridge, UK). The signals were visualized with FDbio-Femto ECL (FD8030, Fdbio science, Hangzhou, China).

\subsection{Statistical Analysis}

All experiments were conducted independently three times and three replications of each experiment were performed. All data were analyzed by SPSS 16.0 statistical software package and Tukey's test $(p<0.05)$ was used for significance analysis.

\section{Results}

\subsection{Structure and Expression Analysis of Sl1}

The Sl1 (Solyc09g089890) gene that was previously reported as one of the highly expressed genes in tomato roots under $\mathrm{Cd}$ stress was selected as the target gene in the current study [25]. We examined the time course of the relative expression level of Sl1 in roots exposed to $\mathrm{Cd}$ stress. After $7 \mathrm{~d}$ treatment, the expression of $S l 1$ reached the peak, which was 4.9-fold of that in control (Figure 1). Moreover, we examined the relative expression of the Sl1 gene in different tissues including leaf, stem, root, flower, and fruit. The results showed that the relative expression level of Sl1 in roots was 6-fold of that in leaves and 1.6-fold of that in stems (Figure 1).

The Sl1 gene locates on chromosome 9 with only one exon on coding sequences (CDS) that encodes 349 amino acids. We used InterPro (https: / / www.ebi.ac.uk/interpro/ (accessed on 20 October 2021)) and Expasy (https: / / web.expasy.org/compute_pi/ (accessed on 22 October 2021)) to analyze thC terminus structure of the Sl1 protein. The results show that the isoelectric point and molecular weight of S11 protein are 8.56 and $40.14 \mathrm{kDa}$, respectively, and S11 contains a RING domain of 127 to 170 amino acids (Figure S2A,B). 
A

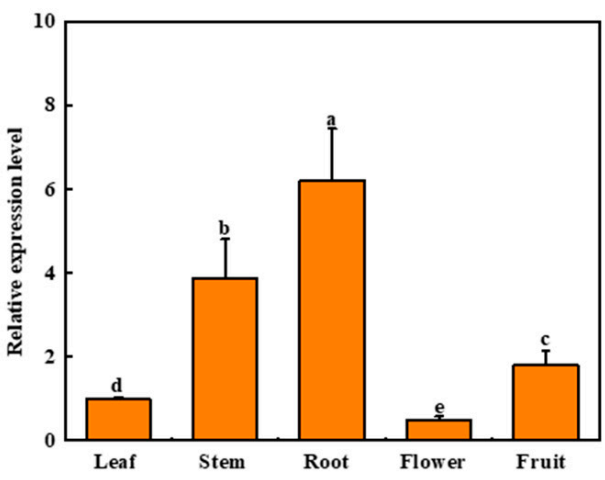

B

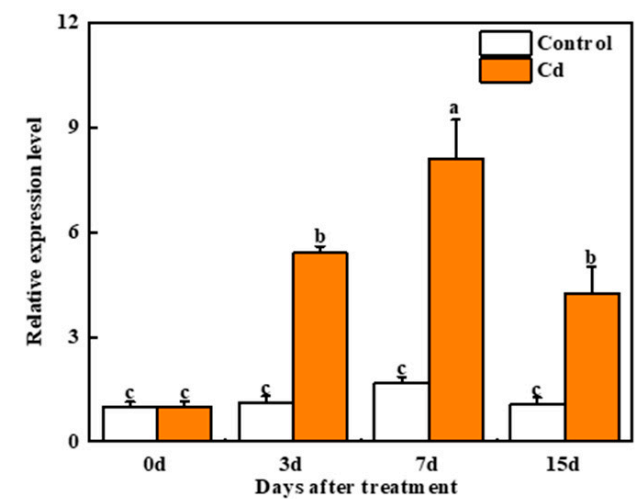

Figure 1. The relative expression level of $S l 1$ in tomato plants. (A) The relative expression level of $S l 1$ in different tissues of tomato. (B) Time course of the relative expression level of Sl1 in tomato root with and without $\mathrm{Cd}$ stress. The data presented here are the average of three biological replicates $( \pm \mathrm{SD})$. Different letters indicate a significant difference $(p<0.05$, Tukey's test).

\subsection{E3 Ubiquitin Ligase Activity and Subcellular Localization of Sl1}

To verify the E3 ubiquitin ligase activity of S11 protein, we successfully purified the maltose-binding protein-S11 (MBP-S11) fusion protein and maltose-binding proteinempty vector (MBP-EV) fusion protein following the manufacturer instructions (Figure 2A). We performed the in vitro ubiquitination assay and showed that S11 protein had selfubiquitination ability when present with E1, E2, and ubiquitin. However, lacking any of E1, E2, or ubiquitin in the reaction system undermined the self-ubiquitination ability of S11. Meanwhile, MBP-EV also did not show self-ubiquitination ability (Figure 2B).

A
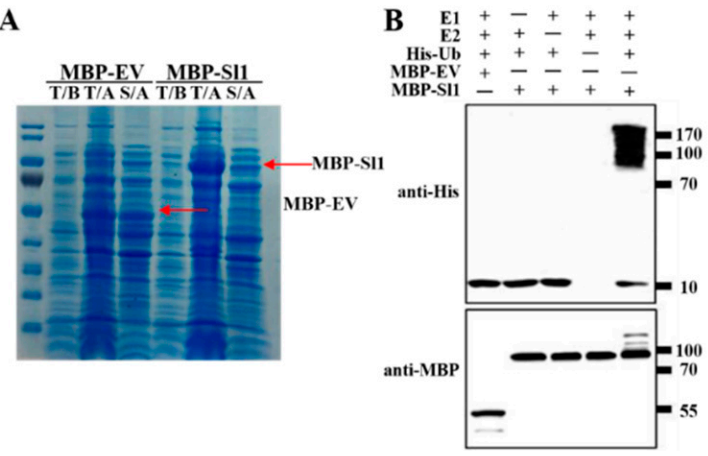

C

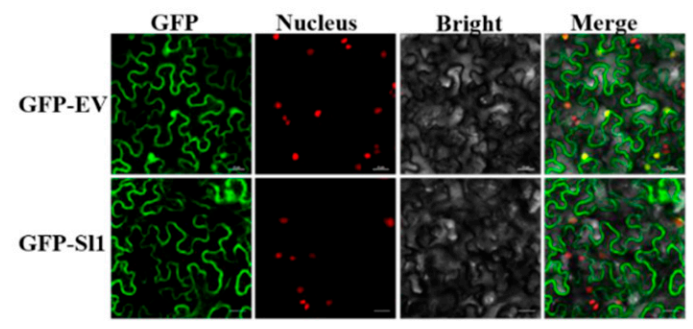

Figure 2. E3 ligase activity and subcellular localization of S11. (A) In vitro expression of MBP-Sl1 and MBP-EV. T: total protein; S: soluble protein; B: before expression; A: after expression. (B) In vitro E3 ligase activity of S11 protein. The reaction system included E1, E2, MBP-S11, and ubiquitin-His, the replacement of MBP-S11 with MBP-EV and the absence of E1, E2, and His- $\mathrm{Ub}$ as control. The Western blot was detected with anti-MBP and anti-His. (C) Subcellular localization of GFP-Sl1 and GFP-EV. The GFP-S11 was transiently expressed in Nicotiana benthamiana (tobacco with nucleuslocated mCherry). Images were pictured by confocal microscope after $48 \mathrm{~h}$ infiltration. Bar $=25 \mu \mathrm{m}$. 
To examine the subcellular localization of S11 protein, we transiently expressed GFP-S11 in transgenic tobacco (with nucleus signal). Images captured by a confocal microscope revealed that the S11 protein is located in plasma membranes rather than the nucleus (Figure 2C).

\subsection{Sl1 Positively Regulates Cd Tolerance in Tomato}

Since the expression of the Sl1 gene was induced by Cd stress, we investigated the tolerance of sl1 mutant lines, wild-type, and Sl1 overexpressing lines to Cd stress. We generated the sl1 mutant lines and Sl1 overexpressing lines as described in the Methods and Materials section (Figure S1). Two sl1 mutant lines were mutated at different sites that both induced early termination of translation. The sl1-1 mutant line was found $311 \mathrm{bp}$ deletion between sgRNA1 and sgRNA2 and the translation was terminated after 98 amino acids (Figure S1B). The sl1-2 mutant line was deleted 1 bp after the protospacer adjacent motif (PAM) of sgRNA1 and the translation was terminated after 89 amino acids (Figure S1B). Two overexpressing lines of Sl1 were checked with Western blot that both had bright bands near the predictive molecular weight (Figure S1C). The phenotypes of sl1 mutants were similar to wild-type plants; however, Sl1 overexpressing lines grew more slowly and showed smaller leaves compared with wild-type plants when they were grown under optimal (nonstress) environments (Figure 3A).

A

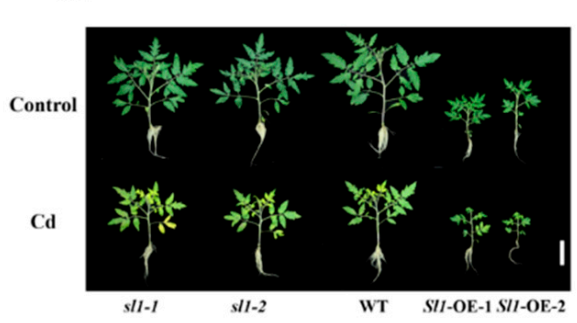

C

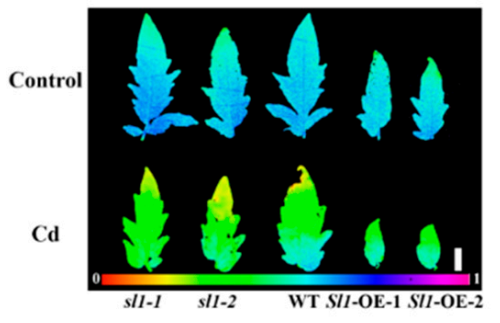

B

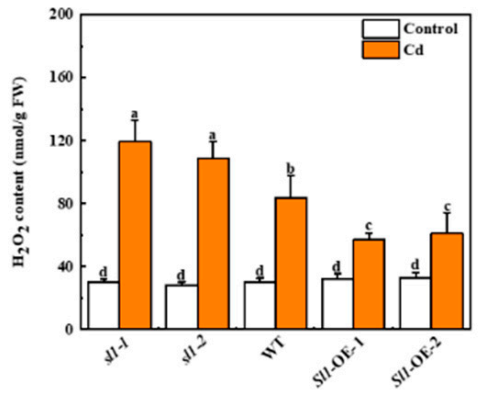

D

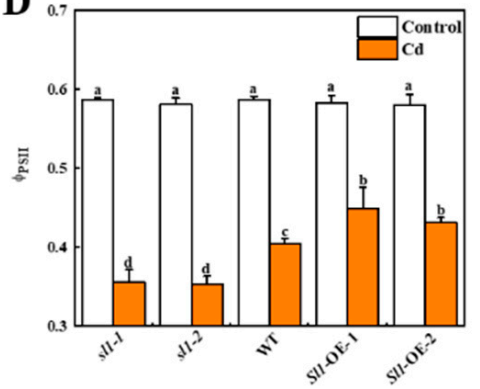

Figure 3. Sl1 positively regulates tomato $\mathrm{Cd}$ tolerance. (A) The phenotype of Sl1 mutant lines (sl1-1/2), wild-type (WT), and Sl1 overexpressing lines (Sl1-OE-1/2) under control and Cd stress after $15 \mathrm{~d}$ treatment. Bar $=10 \mathrm{~cm}$. (B) The content of hydrogen peroxide $\left(\mathrm{H}_{2} \mathrm{O}_{2}\right)$ in the roots of $\mathrm{Sl1}$ mutant lines (sl1-1/2), WT, and Sl1 overexpressing lines (Sl1-OE-1/2) under control and Cd stress after $3 \mathrm{~d}$ treatment. (C,D) the image and level of actual quantum efficiency of PSII photochemistry $\left(\Phi_{\text {PSII }}\right)$ of sl1-1/2, WT, and Sl1-OE-1/2 plants with and without Cd treatment for $15 \mathrm{~d}$. Bar $=1 \mathrm{~cm}$. The data presented here are the average of three biological replicates $( \pm \mathrm{SD})$. Different letters indicate a significant difference $(p<0.05$, Tukey's test).

After $15 \mathrm{~d}$ of Cd treatment, sl1 mutants showed sensitivity to Cd stress, while Sl1-OE showed enhanced tolerance to Cd stress (Figure 3). Compared to control conditions, $C d$-stress-induced changes in leaf size, leaf color, level of $\Phi_{\mathrm{PSI}}$, and content of hydrogen peroxide $\left(\mathrm{H}_{2} \mathrm{O}_{2}\right)$ in sl1 mutants and wild-type plants. In particular, the leaves of sl1 were 
more etiolated than those of wild-type, and the leaf sizes of mutants were smaller than that of wild-type. However, the leaf size and color in $\mathrm{Sl1}$ overexpressing plants were just slightly affected by Cd stress (Figure 3). Since $\mathrm{H}_{2} \mathrm{O}_{2}$ is a major ROS generated under stress conditions, we then detected the accumulation of $\mathrm{H}_{2} \mathrm{O}_{2}$ in roots under $\mathrm{Cd}$ stress. Importantly, the accumulation of $\mathrm{H}_{2} \mathrm{O}_{2}$ increased by $43.1 \%$ and $30.5 \%$ in sl1-1 and sl1-2 mutants, while it decreased by $31.7 \%$ and $26.5 \%$ in two lines of $\mathrm{Sl1}$ overexpressing plants compared with wildtype plants after $\mathrm{Cd}$ treatment, respectively (Figure 3B). Moreover, we detected the value of actual quantum efficiency of PSII photochemistry, $\Phi_{\text {PSII }}$, which reflects the state of photosystem II as a reliable marker of plant health status. As shown in Figure $3 C, D$, the $\Phi_{\mathrm{PSII}}$ value of sl1 mutants, wild-type, and Sl1 overexpressing lines exhibited no significant difference under control conditions. However, the $\Phi_{\mathrm{PSII}}$ levels of sl1-1 and sl1-2 mutants decreased by $12.1 \%$ and $12.7 \%$ respectively, compared with wild-type under Cd stress (Figure 3D). The $\Phi_{\text {PSII }}$ levels of two lines of $S l 1$ overexpressing plants were significantly greater than that in wild-type under Cd stress (Figure 3C,D). These results indicate that Sl1 is critical for alleviating $\mathrm{Cd}$-induced $\mathrm{H}_{2} \mathrm{O}_{2}$ accumulation and damage to the photosynthetic system.

\subsection{Sl1 Promotes Antioxidant Enzyme Activity}

To understand whether $S l 1$ influenced antioxidant enzyme activities in tomato under $\mathrm{Cd}$ stress, we examined the enzyme activities of superoxide dismutase (SOD), catalase (CAT), ascorbate peroxidase (APX), and glutathione reductase (GR). The results showed that $\mathrm{Cd}$ stress increased antioxidant enzyme activities in wild-type and overexpressing lines. However, in sl1 mutant lines, there were no significant differences in antioxidant enzyme activities between control and Cd treatment (Figure 4). The activities of SOD, CAT, APX, and GR in two lines of Sl1 overexpressing plants were all induced compared with wild-type plants under Cd stress (Figure 4). These results suggest that $S l 1$ promotes the activities of antioxidant enzymes under $\mathrm{Cd}$ stress.
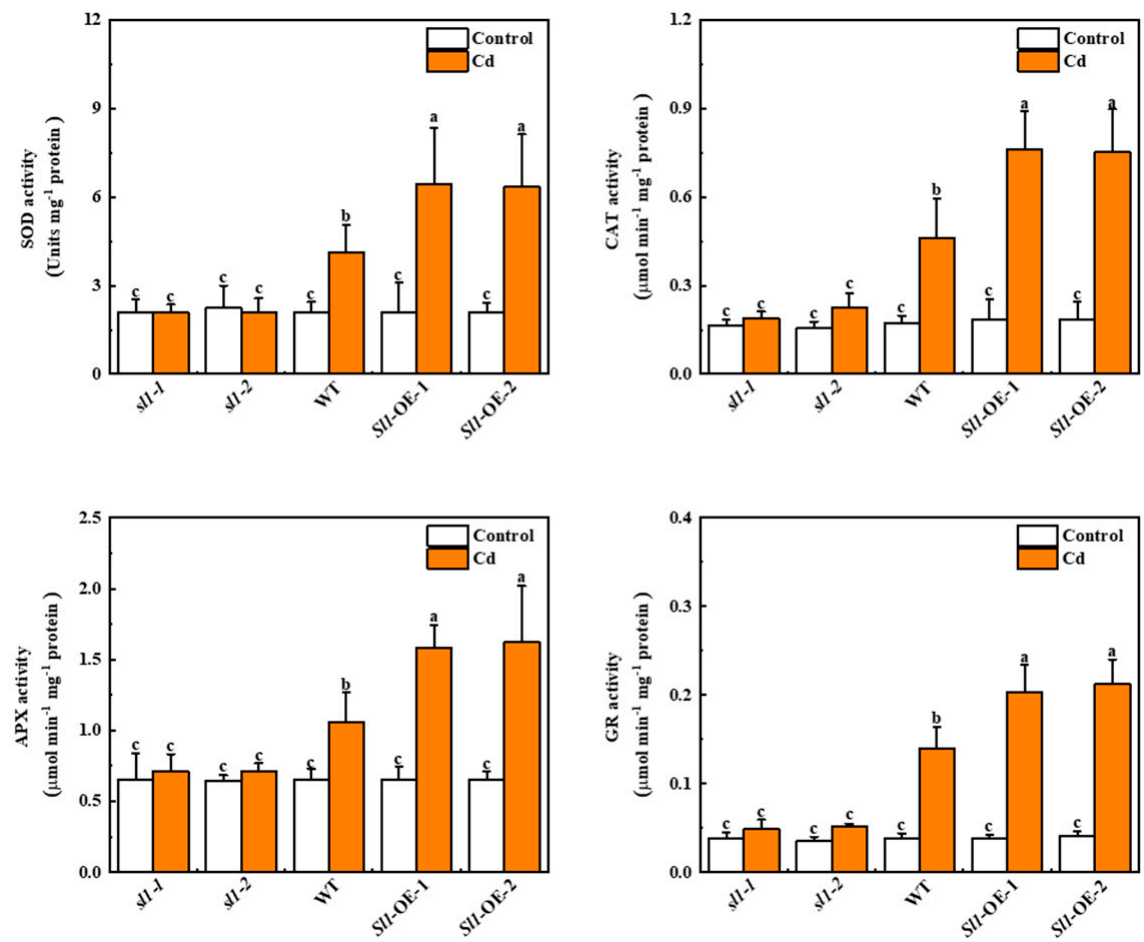

Figure 4. Sl1 promotes antioxidant enzyme activities in tomato plants under Cd stress. The activities of SOD, CAT, APX, and GR in the roots of Sl1 mutant lines (sl1-1/2), wild-type (WT), and Sl1 overexpressing lines (Sl1-OE-1/2) under Cd stress for $3 \mathrm{~d}$. The data presented here are the average of three biological replicates $( \pm S D)$. Different letters indicate a significant difference $(p<0.05$, Tukey's test). 


\subsection{Sl1 Reduces Cd Accumulation and Transportation}

To investigate whether Sl1 is involved in Cd accumulation in tomato plants, we detected the content of $\mathrm{Cd}$ in shoots and roots under $\mathrm{Cd}$ stress. Results revealed that the $\mathrm{Cd}$ content in the roots was higher than that in the shoots (Figure 5A,B). Obviously, overexpression of $\mathrm{Sl1}$ decreased Cd content in both shoots and roots, while Cd content in sl1 mutants significantly increased compared with that in wild-type (Figure 5A,B). The content of $\mathrm{Cd}$ in roots of two $\mathrm{Sl1}$ overexpressing lines both decreased by $25.6 \%$ compared with wild-type, while the Cd content increased by $34.7 \%$ and $41.6 \%$ in roots of $s l 1-1$ and sl1-2 mutants compared with wild-type, respectively. Similarly, $\mathrm{Cd}$ accumulation was also higher in the shoots of sl1 mutants than wild-type plants, while it was lower in the shoots of $S l 1$ overexpressing lines.

A

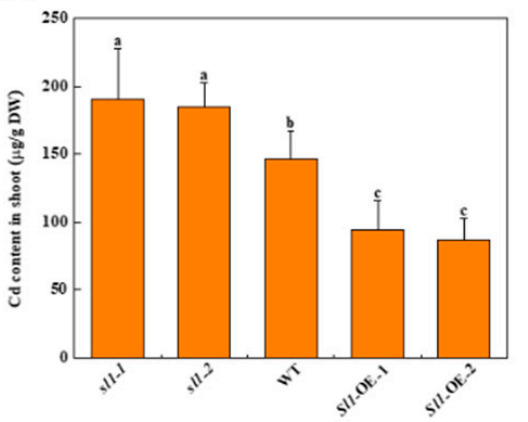

C

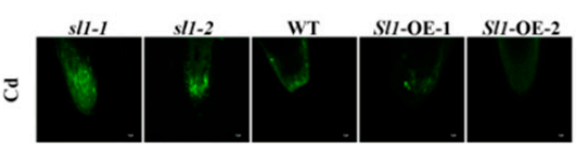

B

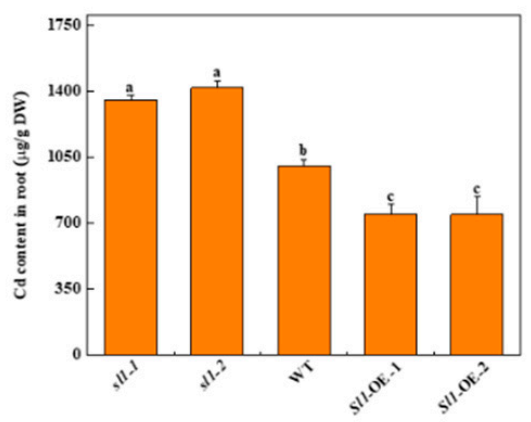

D

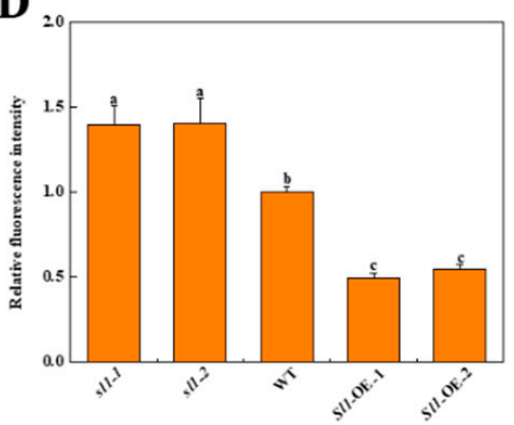

Figure 5. Sl1 decreases $\mathrm{Cd}$ content in tomato plants under $\mathrm{Cd}$ stress. The $\mathrm{Cd}$ content in the shoot (A) and root (B) of Sl1 mutant lines (sl1-1/2), wild-type (WT), and Sl1 overexpressing lines (Sl1-OE-1/2) under $\mathrm{Cd}$ stress for $10 \mathrm{~d}$. (C) $\mathrm{Cd}$ accumulation in tomato root tips stained by the $\mathrm{Cd}$-specific probe Leadmium $^{\mathrm{TM}}$ Green AM. Bar $=25 \mu \mathrm{m}$. (D) Relative fluorescence intensity of Cd staining over tomato root tips of sl1 mutants, wild-type, and Sl1 overexpressing lines after $10 \mathrm{~d} \mathrm{Cd}$ treatment. The relative fluorescence intensity is normalized to the intensity of wild-type in (C). The data presented here are the average of three biological replicates $( \pm S D)$. Different letters indicate a significant difference $(p<0.05$, Tukey's test).

To further investigate whether Sl1 decreased Cd accumulation by altering Cd delivery, we used a Cd-specific probe to study the $\mathrm{Cd}$ distribution in the root tips. The $\mathrm{Cd}$-specific probe stained signals were not detected in the root tips of all plants without $\mathrm{Cd}$ treatment (Figure S2E). However, $\mathrm{Cd}$ treatment induced the accumulation of $\mathrm{Cd}$ in the root tips as reflected by the increased fluorescence intensity. The relative fluorescence intensity of sl1-1 and sl1-2 mutants were 1.40-fold and 1.41-fold of that in wild-type plants, respectively, while the relative fluorescence intensity of Sl1-OE- 1 and Sl1-OE-2 plants were only $49.2 \%$ and $54.7 \%$ of that in wild-type plants (Figure 5C,D).

To investigate how $S l 1$ regulated Cd transportation, we examined the expression of heavy metal transportation-related genes (CAX3, HMA-A, HMA-B, and IRT1). There was no significant difference in the expression of these four genes between sl1 mutants, 
wild-type, and Sl1 overexpressing lines under control conditions. Although these four genes were highly expressed in sl1 mutants under Cd stress, no significant difference was found between control and $\mathrm{Cd}$ treatment in two lines of $\mathrm{Sl1}$ overexpressing plants. We found that Cd stress dramatically increased the transcript level of CAX3 in sl1-1 and sl1-2 mutants under Cd stress, which were 3.2-fold and 3.4-fold of that in wild-type, respectively (Figure 6). The heavy metal transport gene $H M A-A / B$ was also upregulated by Cd stress in sl1-1 and sl1-2 plants by $76.5 \% / 73.6 \%$ and $86.5 \% / 79.9 \%$ compared with wild-type, respectively (Figure 6). Similarly, the expression of IRT1, which plays a prominent role in heavy metal transportation, was also increased by Cd stress in sl1 mutants compared with wild-type plants (Figure 6). These results suggest $S l 1$ potentially functions in resisting heavy metal transportation through repressing the transcription of heavy metal transportation-related genes.
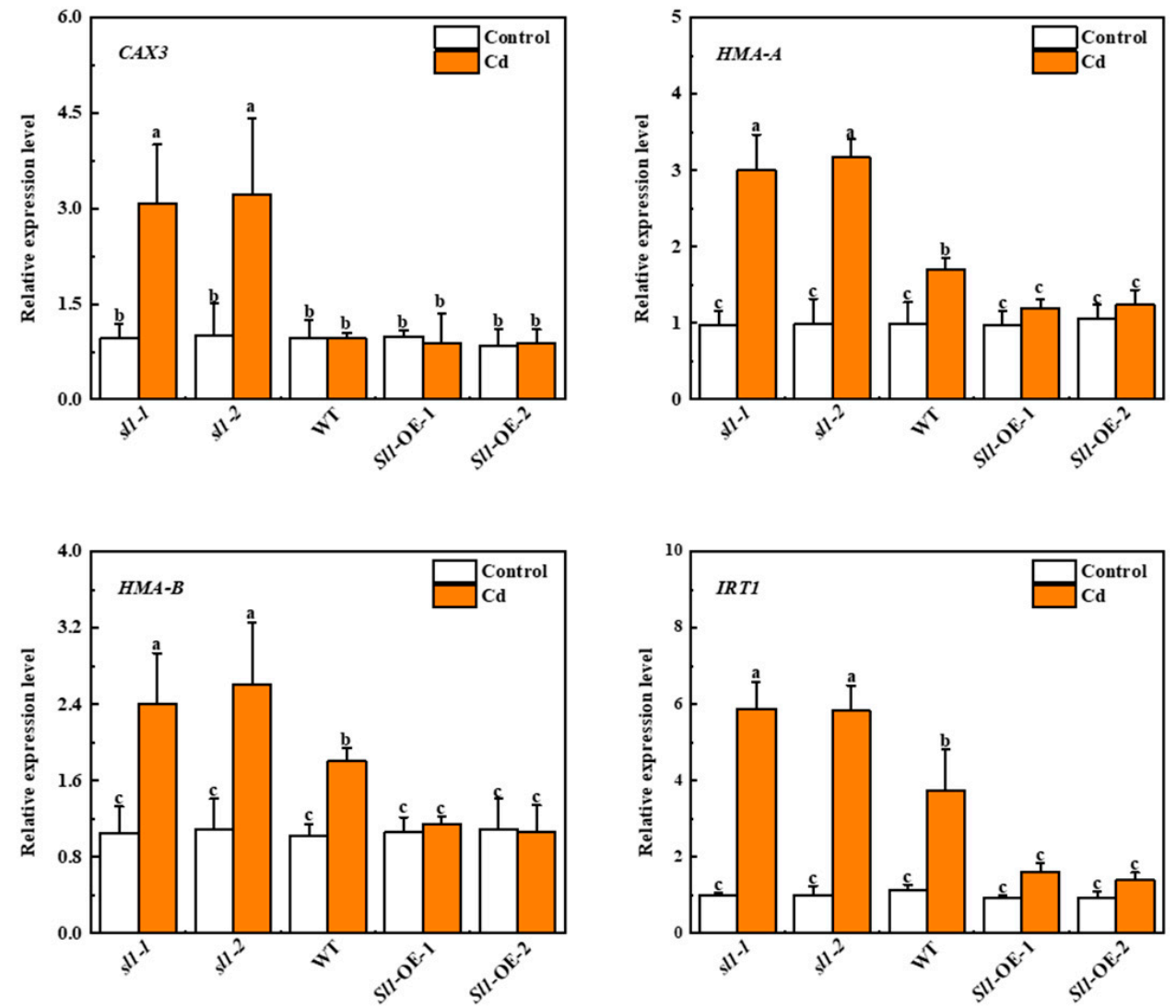

Figure 6. Sl1 negatively regulates the transcripts of genes related to heavy metal transportation. The relative expression of $C A X 3, H M A-A, H M A-B$, and IRT1 in the roots of Sl1 mutant lines (sl1-1/2), wild-type (WT), and $S l 1$ overexpressing lines (Sl1-OE-1/2) under Cd stress for $3 \mathrm{~d}$. The data presented here are the average of three biological replicates $( \pm S D)$. Different letters indicate a significant difference ( $p<0.05$, Tukey's test).

\section{Discussion}

As a significant component of the food chain, plants play a crucial role in the transportation and accumulation of toxic elements such as Cd in humans [44]. Nonetheless, plants also suffer from the stress induced by heavy metals and they address the stress by multiple pathways, including eliminating ROS, resisting heavy metal transportation, and maintaining protein quality $[19,20,24,25]$. The E3 ubiquitin ligase-mediated protein degradation plays an important role in plant stress tolerance $[25,34,36,45,46]$. Here, we characterized a RING-type E3 ubiquitin ligase Sl1, which conferred Cd tolerance in tomato. Our study advances the understanding of the mechanism of UPS-mediated heavy metal tolerance in plants. 
The RING-type E3 ligase is closely associated with plant tolerance to various stress [47]. For example, a C3H2C3-type E3 ubiquitin ligase AtAIRP1 positively regulates ABA-dependent drought tolerance by mediating AtAIRP1 degradation [48,49]. The roles of E3 ubiquitin ligases in the positive regulation of heavy metal stress tolerance have been reported recently in different plant species $[19,25,34,46]$. Overexpression of HIR1 increases the tolerance of rice to As and Cd stress [34]. HIR1 that encodes an E3 ubiquitin ligase interacts with TIP4;1 for resisting heavy metal absorption in rice [34]. Moreover, a U-box type E3 ubiquitin ligase, SIUPS, is highly expressed under Cd stress in tomato. Heterologous expression of SIUPS in yeast increases the concentration of yeast bacterial fluid exposed to $\mathrm{Cd}$ and overexpression of SIUPS in Arabidopsis enhances Cd tolerance [46]. The RING-type E3 ligase AtIDF1 degrades IRT1 to modulate iron homeostasis in Arabidopsis [50]. Heterologous expression of a soybean RING-type E3 ubiquitin ligase gene GmARI1 in Arabidopsis enhances Al tolerance [51]. Furthermore, tomato E3 ubiquitin ligase SIRING1 positively mediates $\mathrm{Cd}$ tolerance by enhancing antioxidant enzyme activities and inhibiting Cd accumulation [19,25]. Similar to SIRING1, Sl1, which is highly expressed under Cd stress in tomato roots, plays a pivotal role in Cd tolerance (Figures 1 and 3). We also found that Sl1 protein possessed the E3 ligase activity and overexpression of $\mathrm{Sl1}$ inhibited $\mathrm{Cd}$ accumulation in tomato. These results are consistent with previous studies [19,34], suggesting that RING-type E3 ubiquitin ligases play crucial roles in regulating metal ion transport.

Cadmium has a broad variety of negative impacts on plants, including oxidative stress, nutrient absorption disruption, and even plant mortality. Antioxidant enzymes such as SOD, POD, CAT, APX, and GR function in collaboration with nonenzymatic antioxidants such as AsA and GSH to prevent Cd-induced oxidative damage [52,53]. Furthermore, GSH directly participates in the synthesis of PCs $[54,55]$. PCs form complexes with Cd that can be compartmentalized into the vacuoles; thus, PCs and other thiols play an important role in determining the sensitivity or tolerance in contrasting genotypes of a plant species [56]. Moreover, studies on the semihalophytic plant Mesembryanthemum crystallinum L. and different Cd hyperaccumulators such as Arabidopsis halleri, Thlaspi caerulescens, Solanum nigrum, and Sedum alfredii species indicate that both antioxidative enzymes and nonenzymatic antioxidants play a vital role in Cd tolerance [57-59]. Previously, we found that an E3 ligase gene SIRING1 positively regulates relative expression levels of CAT, MDHAR, GSH1, and PCS, while it decreases $\mathrm{H}_{2} \mathrm{O}_{2}$ content in tomato under $\mathrm{Cd}$ stress $[19,25]$. Consistent with those studies, $\mathrm{Sl} 1$ overexpression increased the activities of SOD, CAT, APX, and GR, and decreased the content of $\mathrm{H}_{2} \mathrm{O}_{2}$ under $\mathrm{Cd}$ stress in $\mathrm{Sl1}$ overexpressing lines compared with those in wild-type and mutant lines (Figures 3 and 4).

Metal absorption and transportation are critical for plant tolerance to heavy metal stress [44]. The rice E3 ubiquitin ligase OsHIR1 targets TIP4;1 that functions as a heavy metal absorption protein, and thus OsHIR1-induced degradation of TIP4;1 increases rice tolerance to As and Cd stress [34]. Moreover, another RING-type E3 ubiquitin ligase in rice, OsAIR3, regulates protein degradation of molybdate transporter (OsMOT1;3) in rice to increase plant tolerance to arsenate stress [60]. In agreement with these studies, we found that overexpression of $S l 1$ significantly attenuated the relative expression level of several genes related to heavy metal transportation, such as $C A X 3, H M A-A, H M A-B$, and IRT1, along with decreased $\mathrm{Cd}$ content in $S l 1$ overexpressing lines compared with the wild-type and mutant lines (Figures 5 and 6). CAX gene family is an important plant gene family involved in heavy metal transportation [11]. It is plausible that S11 functions as an E3 ubiquitin ligase for the degradation of proteins involved in heavy metal transporters or regulating the abundance of transcription factors upstream of those transporters. Interestingly, heavy-metal-induced stress also results in protein denaturation that aggravates the oxidative stress in plants [24]. Thus, further studies are essentially needed to investigate whether Sl1 could degrade denatured proteins to relieve cell oxidative stress. Moreover, it will also be interesting to study whether Sl1 can coordinate with autophagy to clear denatured proteins [61].

Plants do not have a Cd-selective transporter, therefore, $\mathrm{Cd}$ absorption happens through plasma membrane transporters that also take up other divalent cations [62]. Thus, 
it is indeed difficult to reduce plant $\mathrm{Cd}$ accumulation without compromising plant growth since the majority of well-known $\mathrm{Cd}$ transporters also transport various essential micronutrients such as $\mathrm{Zn}, \mathrm{Fe}, \mathrm{Mn}$, and $\mathrm{Cu}$. Despite the fact that $\mathrm{CAX}$ s are mostly $\mathrm{Ca}^{2+}$ specific transporters, AtCAX2 and AtCAX4 have been demonstrated to transport various other metals, such as Cd, Zn, and Mn in Arabidopsis [58]. Similarly, Fe-specific transporter OsIRT1 has been found to participate in Cd uptake in rice [63]. Thus, suppression of the metal transporter may lead to essential nutrient deficiency and compromised plant growth. In our study, overexpression of Sl1 in tomato not only decreased Cd accumulation but also suppressed plant growth. Reduced $\mathrm{Cd}$ accumulation was associated with decreased expression of several metal transporters such as CAX3, HMA-A, HMA-B, and IRT1. Thus, it is possible that decreased plant growth in Sl1 overexpressing lines could be a consequence of the suppression of the metal transporters under Cd stress. However, reduced growth of the $S l 1$ overexpressing lines under control conditions could be attributed to some other reasons such as impaired hormone homeostasis since the expression levels of $C A X 3, H M A-A$, $H M A-B$, and IRT1 were not significantly different among sl1 mutants, wild-type, and Sl1 overexpressing lines under control conditions. Thus, it would be interesting to explore hormonal involvement in Sl1-regulated plant growth and stress tolerance in future studies.

\section{Conclusions}

In the present study, we characterized an E3 ubiquitin ligase S11 in tomato, which is located in plasma membranes and highly expressed in roots under $\mathrm{Cd}$ stress. For functional characterization of Sl1, we generated knockout lines and overexpressing lines of Sl1 in tomato. The parameters of chlorophyll fluorescence and content of $\mathrm{H}_{2} \mathrm{O}_{2}$ demonstrated that $S I 1$ overexpressing lines suffered less photosystem damage and oxidative stress compared with wild-type and mutants, suggesting that $S l 1$ overexpressing lines are resistant to $\mathrm{Cd}$ stress, while mutant lines are sensitive to Cd stress. Moreover, Sl1 positively regulated antioxidant enzyme activities and negatively mediated gene expression associated with heavy metal transportation. Thus, the current study unveils a novel role of an E3 ubiquitin ligase S11 in tomato that may have potential implications in enhancing heavy metal tolerance in plants. However, identification of the substrate protein of S11 needs further study to precisely verify its association with heavy metal transportation.

Supplementary Materials: The following supporting information can be downloaded at: https: / / www.mdpi.com/article/10.3390/antiox11030456/s1, Figure S1: Generation of Sl1 mutant lines and overexpression lines; Figure S2: Structure analysis of S11 protein and histochemical staining of Cd accumulation of tomato root tips; Table S1: The primers used for qRT-PCR. Supplementary material related to this article can be found in the online version.

Author Contributions: J.Z. and G.J.A. designed the research; C.-X.L., T.Y., H.Z. and Z.-Y.Q. performed the experiments; C.-X.L. and J.Z. analyzed the data; J.Z., C.-X.L. and G.J.A. wrote the manuscript. All authors have read and agreed to the published version of the manuscript.

Funding: This work was supported by the National Key Research and Development Program of China (2019YFD1000300), the National Natural Science Foundation of China (31922078 and 31872089), the Starry Night Science Fund of Zhejiang University Shanghai Institute for Advanced Study (SN-ZJU-SIAS-0011), the National Natural Science Foundation of China (31950410555), and the Ministry of Science and Technology of the People's Republic of China (QNJ20200226001, QNJ2021026001).

Institutional Review Board Statement: Not applicable.

Informed Consent Statement: Not applicable.

Data Availability Statement: Data is contained within the article and Supplementary Materials.

Conflicts of Interest: The authors declare no conflict of interest. 


\section{References}

1. Haider, F.U.; Liqun, C.; Coulter, J.A.; Cheema, S.A.; Wu, J.; Zhang, R.; Wenjun, M.; Farooq, M. Cadmium toxicity in plants: Impacts and remediation strategies. Ecotoxicol. Environ. Saf. 2021, 211, 111887. [CrossRef] [PubMed]

2. Clemens, S.; Ma, J.F. Toxic heavy metal and metalloid accumulation in crop plants and foods. Annu. Rev. Plant Biol. 2016, 67, 489-512. [CrossRef] [PubMed]

3. Zhang, G.; Fukami, M.; Sekimoto, H. Genotypic differences in effects of cadmium on growth and nutrient compositions in wheat J. Plant Nutr. 2000, 23, 1337-1350. [CrossRef]

4. Clemens, S.; Aarts, M.G.M.; Thomine, S.; Verbruggen, N. Plant science: The key to preventing slow cadmium poisoning. Trends Plant Sci. 2013, 18, 92-99. [CrossRef] [PubMed]

5. Rizwan, M.; Ali, S.; Adrees, M.; Ibrahim, M.; Tsang, D.C.W.; Zia-ur-Rehman, M.; Zahir, Z.A.; Rinklebe, J.; Tack, F.M.G.; Ok, Y.S. A critical review on effects, tolerance mechanisms and management of cadmium in vegetables. Chemosphere 2017, 182, 90-105. [CrossRef]

6. Song, Y.; Jin, L.; Wang, X. Cadmium absorption and transportation pathways in plants. Int. J. Phytoremediation 2017, 19, 133-141. [CrossRef]

7. Thomine, S.; Lelièvre, F.; Debarbieux, E.; Schroeder, J.I.; Barbier-Brygoo, H. AtNRAMP3, a multispecific vacuolar metal transporter involved in plant responses to iron deficiency. Plant J. 2003, 34, 685-695. [CrossRef]

8. Thomine, S.; Wang, R.; Ward, J.M.; Crawford, N.M.; Schroeder, J.I. Cadmium and iron transport by members of a plant metal transporter family in Arabidopsis with homology to Nramp genes. Proc. Natl. Acad. Sci. USA 2000, 97, 4991-4996. [CrossRef]

9. Hirschi, K.D. Expression of Arabidopsis CAX1 in tobacco: Altered calcium homeostasis and increased stress sensitivity. Plant Cell 1999, 11, 2113-2122. [CrossRef]

10. Rea, P.A.; Li, Z.S.; Lu, Y.P.; Drozdowicz, Y.M.; Martinoia, E. From vacuolar GS-X pumps to multispecific ABC transporters. Annu. Rev. Plant Physiol. Plant Mol. Biol. 1998, 49, 727-760. [CrossRef]

11. Shigaki, T.; Pittman, J.K.; Hirschi, K.D. Manganese specificity determinants in the Arabidopsis metal/ $\mathrm{H}^{+}$antiporter CAX2. J. Biol. Chem. 2003, 278, 6610-6617. [CrossRef] [PubMed]

12. Blaudez, D.; Kohler, A.; Martin, F.; Sanders, D.; Chalot, M. Poplar metal tolerance protein 1 confers zinc tolerance and is an oligomeric vacuolar zinc transporter with an essential leucine zipper motif. Plant Cell 2003, 15, 2911-2928. [CrossRef] [PubMed]

13. Zulfiqar, U.; Ayub, A.; Hussain, S.; Waraich, E.A.; El-Esawi, M.A.; Ishfaq, M.; Ahmad, M.; Ali, N.; Maqsood, M.F. Cadmium toxicity in plants: Recent progress on morpho-physiological effects and remediation strategies. J. Soil Sci. Plant Nutr. 2021, 22, 1-58. [CrossRef]

14. Choppala, G.; Saifullah; Bolan, N.; Bibi, S.; Iqbal, M.; Rengel, Z.; Kunhikrishnan, A.; Ashwath, N.; Ok, Y.S. Cellular mechanisms in higher plants governing tolerance to cadmium toxicity. Crit. Rev. Plant Sci. 2014, 33, 374-391. [CrossRef]

15. Alyemeni, M.N.; Ahanger, M.A.; Wijaya, L.; Alam, P.; Bhardwaj, R.; Ahmad, P. Selenium mitigates cadmium-induced oxidative stress in tomato (Solanum lycopersicum L.) plants by modulating chlorophyll fluorescence, osmolyte accumulation, and antioxidant system. Protoplasma 2018, 255, 459-469. [CrossRef]

16. Sharma, S.S.; Dietz, K.-J. The relationship between metal toxicity and cellular redox imbalance. Trends Plant Sci. 2009, 14, 43-50. [CrossRef]

17. Hernández, L.E.; Sobrino-Plata, J.; Montero-Palmero, M.B.; Carrasco-Gil, S.; Flores-Cáceres, M.L.; Ortega-Villasante, C.; Escobar C. Contribution of glutathione to the control of cellular redox homeostasis under toxic metal and metalloid stress. J. Exp. Bot. 2015, 66, 2901-2911. [CrossRef]

18. Ahammed, G.J.; Wu, M.; Wang, Y.; Yan, Y.; Mao, Q.; Ren, J.; Ma, R.; Liu, A.; Chen, S. Melatonin alleviates iron stress by improving iron homeostasis, antioxidant defense and secondary metabolism in cucumber. Sci. Hortic. 2020, 265, 109205. [CrossRef]

19. Ahammed, G.J.; Li, C.-X.; Li, X.; Liu, A.; Chen, S.; Zhou, J. Overexpression of tomato RING E3 ubiquitin ligase gene SlRING1 confers cadmium tolerance by attenuating cadmium accumulation and oxidative stress. Physiol. Plant. 2021, 173, 449-459. [CrossRef]

20. Hasan, M.K.; Ahammed, G.J.; Sun, S.; Li, M.; Yin, H.; Zhou, J. Melatonin inhibits cadmium translocation and enhances plant tolerance by regulating sulfur uptake and assimilation in Solanum lycopersicum L. J. Agric. Food Chem. 2019, 67, 10563-10576. [CrossRef]

21. Ahmad, P.; Jaleel, C.A.; Salem, M.A.; Nabi, G.; Sharma, S. Roles of enzymatic and nonenzymatic antioxidants in plants during abiotic stress. Crit. Rev. Biotechnol. 2010, 30, 161-175. [CrossRef] [PubMed]

22. Ahammed, G.J.; Xu, W.; Liu, A.; Chen, S. Endogenous melatonin deficiency aggravates high temperature-induced oxidative stress in Solanum lycopersicum L. Environ. Exp. Bot. 2019, 161, 303-311. [CrossRef]

23. Cobbett, C.; Goldsbrough, P. Phytochelatins and metallothioneins: Roles in heavy metal detoxification and homeostasis. Annu. Rev. Plant Biol. 2002, 53, 159-182. [CrossRef] [PubMed]

24. Hasan, M.K.; Cheng, Y.; Kanwar, M.K.; Chu, X.-Y.; Ahammed, G.J.; Qi, Z.-Y. Responses of plant proteins to heavy metal stress-A review. Front. Plant Sci. 2017, 8, 01492. [CrossRef] [PubMed]

25. Qi, Z.-Y.; Ahammed, G.J.; Jiang, C.-Y.; Li, C.-X.; Zhou, J. The E3 ubiquitin ligase gene SlRING1 is essential for plant tolerance to cadmium stress in Solanum lycopersicum. J. Biotechnol. 2020, 324, 239-247. [CrossRef]

26. Xu, F.-Q.; Xue, H.-W. The ubiquitin-proteasome system in plant responses to environments. Plant Cell Environ. 2019, 42, 2931-2944. [CrossRef] 
27. Hua, Z.; Vierstra, R.D. The cullin-RING ubiquitin-protein ligases. Annu. Rev. Plant Biol. 2011, 62, 299-334. [CrossRef]

28. Bosu, D.R.; Kipreos, E.T. Cullin-RING ubiquitin ligases: Global regulation and activation cycles. Cell Div. 2008, 3, 7. [CrossRef]

29. Stone, S.L. The role of ubiquitin and the 26S proteasome in plant abiotic stress signaling. Front. Plant Sci. 2014, 5, 00135. [CrossRef]

30. Guerra, D.; Mastrangelo, A.M.; Lopez-Torrejon, G.; Marzin, S.; Schweizer, P.; Stanca, A.M.; del Pozo, J.C.; Cattivelli, L.; Mazzucotelli, E. Identification of a protein network interacting with TdRF1, a wheat RING ubiquitin ligase with a protective role against cellular dehydration. Plant Physiol. 2011, 158, 777-789. [CrossRef]

31. Shu, K.; Yang, W. E3 ubiquitin ligases: Ubiquitous actors in plant development and abiotic stress responses. Plant Cell Physiol. 2017, 58, 1461-1476. [CrossRef] [PubMed]

32. Kraft, E.; Stone, S.L.; Ma, L.; Su, N.; Gao, Y.; Lau, O.-S.; Deng, X.-W.; Callis, J. Genome analysis and functional characterization of the E2 and RING-type E3 ligase ubiquitination enzymes of Arabidopsis. Plant Physiol. 2005, 139, 1597-1611. [CrossRef] [PubMed]

33. Hotton, S.K.; Callis, J. Regulation of cullin RING ligases. Annu. Rev. Plant Biol. 2008, 59, 467-489. [CrossRef]

34. Lim, S.D.; Hwang, J.G.; Han, A.R.; Park, Y.C.; Lee, C.; Ok, Y.S.; Jang, C.S. Positive regulation of rice RING E3 ligase OsHIR1 in arsenic and cadmium uptakes. Plant Mol. Biol. 2014, 85, 365-379. [CrossRef] [PubMed]

35. Fillatti, J.J.; Kiser, J.; Rose, R.; Comai, L. Efficient transfer of a glyphosate tolerance gene into tomato using a binary Agrobacterium Tumefaciens vector. Bio/technology 1987, 5, 726-730. [CrossRef]

36. Zhang, Y.; Yang, C.; Li, Y.; Zheng, N.; Chen, H.; Zhao, Q.; Gao, T.; Guo, H.; Xie, Q. SDIR1 Is a RING finger E3 ligase that positively regulates stress-responsive abscisic acid signaling in Arabidopsis. Plant Cell 2007, 19, 1912-1929. [CrossRef]

37. Liao, Y.; Tian, M.; Zhang, H.; Li, X.; Wang, Y.; Xia, X.; Zhou, J.; Zhou, Y.; Yu, J.; Shi, K.; et al. Salicylic acid binding of mitochondrial alpha-ketoglutarate dehydrogenase $\mathrm{E} 2$ affects mitochondrial oxidative phosphorylation and electron transport chain components and plays a role in basal defense against tobacco mosaic virus in tomato. New Phytol. 2015, 205, 1296-1307. [CrossRef]

38. Chi, C.; Xu, X.; Wang, M.; Zhang, H.; Fang, P.; Zhou, J.; Xia, X.; Shi, K.; Zhou, Y.; Yu, J. Strigolactones positively regulate abscisic acid-dependent heat and cold tolerance in tomato. Hortic. Res. 2021, 8, 237. [CrossRef]

39. Willekens, H.; Chamnongpol, S.; Davey, M.; Schraudner, M.; Langebartels, C.; Van Montagu, M.; Inzé, D.; Van Camp, W. Catalase is a sink for $\mathrm{H}_{2} \mathrm{O}_{2}$ and is indispensable for stress defence in $\mathrm{C} 3$ plants. EMBO J. 1997, 16, 4806-4816. [CrossRef]

40. Xia, X.-J.; Wang, Y.-J.; Zhou, Y.-H.; Tao, Y.; Mao, W.-H.; Shi, K.; Asami, T.; Chen, Z.; Yu, J.-Q. Reactive oxygen species are involved in brassinosteroid-induced stress tolerance in cucumber. Plant Physiol. 2009, 150, 801-814. [CrossRef]

41. Li, M.-Q.; Hasan, M.K.; Li, C.-X.; Ahammed, G.J.; Xia, X.-J.; Shi, K.; Zhou, Y.-H.; Reiter, R.J.; Yu, J.-Q.; Xu, M.-X.; et al. Melatonin mediates selenium-induced tolerance to cadmium stress in tomato plants. J. Pineal Res. 2016, 61, 291-302. [CrossRef] [PubMed]

42. Wang, F.; Chen, X.; Dong, S.; Jiang, X.; Wang, L.; Yu, J.; Zhou, Y. Crosstalk of PIF4 and DELLA modulates CBF transcript and hormone homeostasis in cold response in tomato. Plant Biotechnol. J. 2020, 18, 1041-1055. [CrossRef] [PubMed]

43. Wang, Y.; Cao, J.-J.; Wang, K.-X.; Xia, X.-J.; Shi, K.; Zhou, Y.-H.; Yu, J.-Q.; Zhou, J. BZR1 mediates brassinosteroid-induced autophagy and nitrogen starvation in tomato. Plant Physiol. 2018, 179, 671-685. [CrossRef] [PubMed]

44. Jogawat, A.; Yadav, B.; Chhaya; Narayan, O.P. Metal transporters in organelles and their roles in heavy metal transportation and sequestration mechanisms in plants. Physiol. Plant. 2021, 173, 259-275. [CrossRef] [PubMed]

45. Zhang, H.; Cui, F.; Wu, Y.; Lou, L.; Liu, L.; Tian, M.; Ning, Y.; Shu, K.; Tang, S.; Xie, Q. The RING finger ubiquitin E3 ligase SDIR1 targets SDIR1-INTERACTING PROTEIN1 for degradation to modulate the salt stress response and ABA signaling in Arabidopsis. Plant Cell 2015, 27, 214-227. [CrossRef]

46. Dong, D.; Jing, C.; Li, Q.; Cao, Y.; Chen, C.; Yu, L.; Dong, Y.; Jin, X. SlUPS, a U-box type E3 ubiquitin ligase gene of Lycopersicon esculentum Mill., confers the capacity of cadmium stress resistance in Arabidopsis. N. Zeal. J. Crop Hortic. Sci. 2021, 50, 1-16. [CrossRef]

47. Lyzenga, W.J.; Stone, S.L. Abiotic stress tolerance mediated by protein ubiquitination. J. Exp. Bot. 2011, 63, 599-616. [CrossRef]

48. Oh, T.R.; Yu, S.G.; Yang, H.W.; Kim, J.H.; Kim, W.T. AtKPNB1, an Arabidopsis importin- $\beta$ protein, is downstream of the RING E3 ubiquitin ligase AtAIRP1 in the ABA-mediated drought stress response. Planta 2020, 252, 93. [CrossRef]

49. Ryu, M.Y.; Cho, S.K.; Kim, W.T. The Arabidopsis C3H2C3-type RING E3 ubiquitin ligase AtAIRP1 is a positive regulator of an abscisic acid-dependent response to drought stress. Plant Physiol. 2010, 154, 1983-1997. [CrossRef]

50. Shin, L.-J.; Lo, J.-C.; Chen, G.-H.; Callis, J.; Fu, H.; Yeh, K.-C. IRT1 DEGRADATION FACTOR1, a RING E3 ubiquitin ligase, regulates the degradation of IRON-REGULATED TRANSPORTER1 in Arabidopsis. Plant Cell 2013, 25, 3039-3051. [CrossRef]

51. Zhang, X.; Wang, N.; Chen, P.; Gao, M.; Liu, J.; Wang, Y.; Zhao, T.; Li, Y.; Gai, J. Overexpression of a soybean ariadne-like ubiquitin ligase gene GmARI1 enhances aluminum tolerance in Arabidopsis. PLoS ONE 2014, 9, e111120. [CrossRef] [PubMed]

52. Hasanuzzaman, M.; Bhuyan, M.H.M.B.; Anee, T.I.; Parvin, K.; Nahar, K.; Mahmud, J.A.; Fujita, M. Regulation of ascorbateglutathione pathway in mitigating oxidative damage in plants under abiotic stress. Antioxidants 2019, 8, 384. [CrossRef] [PubMed]

53. Dvořák, P.; Krasylenko, Y.; Zeiner, A.; Šamaj, J.; Takáč, T. Signaling toward reactive oxygen species-scavenging enzymes in plants. Front. Plant Sci. 2021, 11, 618835. [CrossRef] [PubMed]

54. Jozefczak, M.; Remans, T.; Vangronsveld, J.; Cuypers, A. Glutathione is a key player in metal-induced oxidative stress defenses. Int. J. Mol. Sci. 2012, 13, 3145-3175. [CrossRef]

55. Seth, C.S.; Remans, T.; Keunen, E.; Jozefczak, M.; Gielen, H.; Opdenakker, K.; Weyens, N.; Vangronsveld, J.; Cuyoers, A. Phytoextraction of toxic metals: A central role for glutathione. Plant Cell Environ. 2012, 35, 334-346. [CrossRef] 
56. Maghrebi, M.; Baldoni, E.; Lucchini, G.; Vigani, G.; Valè, G.; Sacchi, G.A.; Nocito, F.F. Analysis of Cadmium Root Retention for Two Contrasting Rice Accessions Suggests an Important Role for OsHMA2. Plants 2021, 10, 806. [CrossRef]

57. Liu, H.; Zhao, H.; Wu, L.; Liu, A.; Zhao, F.-J.; Xu, W. Heavy metal ATPase 3 (HMA3) confers cadmium hypertolerance on the cadmium/zinc hyperaccumulator Sedum plumbizincicola. New Phytol. 2017, 215, 687-698. [CrossRef]

58. Huang, X.; Duan, S.; Wu, Q.; Yu, M.; Shabala, S. Reducing Cadmium Accumulation in Plants: Structure-Function Relations and Tissue-Specific Operation of Transporters in the Spotlight. Plants 2020, 9, 223. [CrossRef]

59. Śliwa-Cebula, M.; Kaszycki, P.; Kaczmarczyk, A.; Nosek, M.; Lis-Krzyścin, A.; Miszalski, Z. The Common Ice Plant (Mesembryanthemum crystallinum L.)-Phytoremediation Potential for Cadmium and Chromate-Contaminated Soils. Plants 2020, 9, 1230. [CrossRef]

60. Kim, J.H.; Lee, J.E.; Jang, C.S. Regulation of Oryza sativa molybdate transporter1;3 degradation via RING finger E3 ligase OsAIR3. J. Plant Physiol. 2021, 264, 153484. [CrossRef]

61. Zhou, X.-M.; Zhao, P.; Wang, W.; Zou, J.; Cheng, T.-H.; Peng, X.-B.; Sun, M.-X. A comprehensive, genome-wide analysis of autophagy-related genes identified in tobacco suggests a central role of autophagy in plant response to various environmental cues. DNA Res. 2015, 22, 245-257. [CrossRef] [PubMed]

62. Zakaria, Z.; Zulkafflee, N.S.; Mohd Redzuan, N.A.; Selamat, J.; Ismail, M.R.; Praveena, S.M.; Tóth, G.; Abdull Razis, A.F. Understanding Potential Heavy Metal Contamination, Absorption, Translocation and Accumulation in Rice and Human Health Risks. Plants 2021, 10, 1070. [CrossRef] [PubMed]

63. Takahashi, R.; Ito, M.; Kawamoto, T. The Road to Practical Application of Cadmium Phytoremediation Using Rice. Plants 2021, 10, 1926. [CrossRef] [PubMed] 